\title{
The Use of Connectors in Argumentative Writing by EFL Undergraduate Students from the University of Burundi: A Quantitative Analysis
}

\section{Oda Kayonde}

* Correspondence:

oda.kayonde@ub.edu.bi

1. Department of English Language and

Literature, Faculty of Arts and Social

Sciences, University of Burundi

Received: 15 March 2021

Revision: 5 May 2021

Accepted: 4 June 2021

Published online: 20 September 2021

\begin{abstract}
Although there is a large body of literature on the use of connectors by EFL learners in argumentative writing, African language learner groups are not represented and most studies have adopted a cross-sectional approach. This paper seeks to analyze how frequently connectors are used on the basis of pseudo-longitudinal data from first, second, and third-year undergraduate students from the Institute for Applied Pedagogy, University of Burundi. The study adopted the corpus linguistic and quantitative approaches. The data were collected through 2 writing assignments given to students in 2019 . In total, 622 essays, amounting to 306,664-word tokens, were collected. Data preparation followed three steps, namely, typing the handwritten essays, preparing the TXT files, and metadata for the corpus. The latter was searched using AntConc tool, on the basis of a comprehensive list of 95 connectors, classified into 6 categories. The tool availed frequency information, that is, how often each connector occurs in the corpus. Percentages were computed using XLS facility and are presented in tables and graphs. Results indicate that 19 connectors were frequently used by learners, the most frequent ones being those which add information followed by those expressing a result relationship. However, connectors expressing transition and summation were found to be rarely used in the corpus. Another discovery is that learners in all three years of study seem to have the same preferences in terms of connectors. Furthermore, cases of misuse such as wrong combinations and incorrect spelling, semantic, stylistic and syntactic errors were observed at all levels. The findings of this study can be useful to learners, teachers, and material designers.
\end{abstract}

Keywords: connectors, EFL learners, preference, $\underline{\text { misuse, }} \underline{\text { argumentative }}$ writing 


\section{Introduction}

Both writing and speech make use of important devices referred to as connectors. Connectors help join different text units, that is, words, phrases, sentences, clauses, and paragraphs together. According to Leech and Svartvik (1994 as cited in Tapper, 2005), connectors called connectives in the latter, function as "cohesive 'signposts' in discourse that help guide the reader or listener through the message by signalling how successive units are related" (p.116). Some examples are in addition, because, therefore, etc. It should be indicated that many other terms have been used in the literature, namely, conjunctions (Halliday \& Hassan, 1976), linking adverbials (Biber, Johansson, Leech, Conrad, \& Finegan, 1999), connectives (Byrne, 1979; Leki, 1989; Tang \& Ng, 1995) to name but a few. For consistency's sake, the term connector is used in this study.

The use of connectors in learner writing has received much attention these last decades. Many studies have shown that the use of connectors by learners is problematic. Tang and $\mathrm{Ng}$ (1995), for example, have pointed out that "the misuse of connectors is an almost universal feature of English as a Second Language (ESL) students' writing" (p.105). Research conducted on the use of connectors by English as a Foreign Language (EFL) learner writers seems to suggest that learners tend to overuse, underuse and/or misuse connectors. One example of overuse much cited in the literature concerns the additive connectors - called listing connectors in this study (Field \&Yip, 1992; Granger \& Tyson, 1996; Güneş, 2017; Tang \& Ng, 1995 as cited in Granger, 1996, p.20).

\subsection{Statement of the Problem}

There is abundant literature on the use of connectors by EFL learners. As a result, numerous EFL learner groups have so far been investigated. Examples include the French EFL learners (Gilquin \& Granger, 2015; Granger \& Tyson, 1996), the Swedish EFL learners (Tapper, 2005), Indonesian EFL learners (Mahendra \& Dewi, 2017), the Brazilian EFL learners (Matte, 2017); Iranian EFL learners (Sabzevari, Haghverdi, \& Bria, 2016), the Turkish EFL learners (Güneş, 2017; Uçar \& Yukselir, 2017), Arab EFL learners (Al Mughrabi, 2017), and Chinese EFL learners (Milton \& Tsang, 1993). An examination of the existing literature shows that African EFL learner groups, in general and Burundian EFL learner group in particular, have not been subject of investigation whatsoever. Moreover, from the researcher' $s$ teaching experience of writing at the University of Burundi, it seems that the Burundian EFL learner group has the same challenges as other English learner groups already investigated. Another problem is that the studies which were carried out adopted a cross-sectional approach, that is, they targeted learners from different domains of study, such as science and humanities. It is also important to use longitudinal data in order to examine the use of connectors by EFL learners. Therefore, the present paper is based on pseudo-longitudinal data collected in first, second- and third-year students from the Institute for Applied Pedagogy, at the University of Burundi. Truly longitudinal data would be more interesting but the option of using pseudo-longitudinal data was dictated by to the time constraint. This study provides valuable information which can be used by both teachers and learners. In addition, the results can be used by materials designers for a better teaching of English connectors.

\subsection{Research Questions}

The present study was guided by the following research questions:

1. What are the connectors used by EFL learners from the Institute for Applied Pedagogy in argumentative writing?

2. What are the most frequently used connectors in argumentative writing by learners from the Institute for Applied?

3. What is the accuracy level of EFL learners from the Institute for Applied Pedagogy in the use of connectors in argumentative writing?

\section{Literature Review}

Many authors have indicated that the use of connectors in one's discourse is paramount in the interpretation of the message by the hearer/listener or the reader. Biber et al. (1999) indicate that "the primary function of connectors [referred to in their study as linking adverbials] is to state the speaker/writer's perception of the relationship between two units of discourse (p.875). As such, according to the same authors, such linking devices are "important in creating textual cohesion" (Biber et al., 1999). In other words, the use of connectors in one's speech or writing facilitates the interpretation process of the discourse, on the part of hearer or reader.

The idea of connectors as facilitating devices for discourse interpretation is also expressed by Celce-Murcia and Larsen-Freeman (1999 as cited in Sabzevari, Haghverdi, \& Biria, 2016). According to these authors, adverbials (as 
they are called in their study), are defined as "lexical expressions that may add little or no propositional content by themselves but they serve to specify the relationship among sentences in oral and written discourse, thereby leading the reader to the feeling that the sentences hang together or make sense" (p.283). Given their role in the discourse, connectors have been referred to as signposts in discourse interpretation (Carrió-Pastor, 2013; Leech \& Svartvik, 1994; Sabzevari, Haghverdi, \& Biria, 2016; Tapper, 2005).

An interesting experiment was conducted by Mauranen (1993). The study compared two samples of academic texts, that is, a sample of texts containing connectors and the same sample from which connectors had been removed. The study found that the sample which contained connectors was perceived to be more logical, convincing, and authoritative than the sample with no connectors. The results of this study led to the conclusion that the use of connectors in discourse plays a facilitating role in the understanding of the text.

Whereas it is almost agreed among scholars that the use of connectors in discourse is helpful in the interpretation of a message, it is obvious that these connectors have to be used appropriately in order to fulfill their role of facilitators. This is in line with Sabzevari, Haghverdi and Biria's (2016) comment that "these logical connectors, if placed appropriately, function as signposts, guiding the reader through the discourse." In other words, if connectors are used inappropriately, they may even mislead readers. Studies carried out on the use of connectors by non-native learners of English suggest that their use is problematic. Most studies have shown that EFL learners tend to overuse, underuse, or misuse connectors in their writing.

Sabzevari, Haghverdi, and Biria (2016) analyzed how Iranian EFL students used connectors (referred to as conjunctive adverbials) in their writing. The study was based on 30 articles written by EFL learners and 30 articles written by native writers in the field of Applied Linguistics. Celce-Murcia and Larsen-Freeman's (1999) framework of connectors, a modified version of Halliday and Hassan's classification (1976) was used. This model incudes 4 categories of connectors, namely, additive, adversative, causal, and temporal connectors. The study found that there was a similar tendency for both groups (EFL and native writers) to use a set of connectors. In addition, the word-level analysis showed that EFL writers used more connectors than the native group while the sentence-level analysis showed that the native speakers used more connectors than the EFL group. Moreover, the EFL group had stylistic difficulties with some of the connectors such as besides and therefore.

Another interesting study was carried out by Güneş (2017). It investigated how Turkish doctoral students used connectors (called linking adverbials) in their academic writing. AntConc software was utilized for the quantitative analysis of connectors used in students' doctoral dissertations. The study found that the Turkish doctoral students overused connectors and that the most overused ones were those expressing addition and result.

Still another study by Mahendra and Dewi (2017) examined how Indonesian students from Ganesha University of Education used connectors in their academic writing productions with focus on errors made. Ant Conc tool was used to analyze the data. The study found that the most difficult connectors (called transitions in their study) were however, in fact, moreover, also, either and as well as.

Yet another study was carried out by Tang and $\mathrm{Ng}$ (1995). It was conducted on the basis of 32 copies of essays collected from first year students at City University of Hong Kong (18 essays from Science students and 14 essays from Art students). The study sought to find out what connectors were commonly used, their positioning in the sentence as well as cases of misuse of connectors. They used Quirk et al.'s (1985) taxonomy of connectors. The Longman concordancer was used to find out the frequency for connectors. The study found that the most frequently used connectors were in the additive, resultive, and contrastive categories. It was also revealed that within additive connectors and was the most popular. In addition, inferential, transitional and summative connectors were found to be rarely used. According to the authors, this indicates that students are weak in explaining and developing ideas (Tang \& Ng, 1995, p.112).

Matter (2017) carried out an investigation on how Brazilian students studying in British universities used connectors in comparison with how native speakers used them. The study was based on a corpus of Brazilian academic written English (BrAWE) amounting to 657,089 words and a corpus of British academic written English (BAWE) totaling 6,968,089 words. Biber et al.'s (1999) framework of connectors (enumeration and addition, apposition, Result/inference, Contrast/ concession and Transition) guided the study. Sketch engine was used to search the corpus and Log-Likelihood $(L L)$ helped to test statistical significance. The study found that Brazilian students overused connectors as a whole, specifically connectors expressing additional ideas. 
The examination of existing literature has revealed that most of the previous studies on connectors adopted a crosssectional approach. This idea is supported by Gilquin's (2015) comment in her discussion on learner corpus typology. She states that many studies have adopted a cross-sectional approach, and that, according to her, this is "partly explained by the fact that it is easier to collect a cross- sectional corpus than a longitudinal one" (p.28). Following up a class of students requires more investment in terms of time, energy, and probably financial means. This state of affairs explains why there exist more cross-sectional studies than longitudinal ones.

One study which adopted a longitudinal approach was carried out by Al Mughrabi (2017). This study investigated the frequency of errors in the use of connectors (referred to as Discourse Markers) by 40 English majors selected from first, second, third, and fourth year at Hashemite University in Jordan. Four categories of connectors were targeted, namely additive, causative, adversative, and temporal (cf. Halliday \& Hassan's framework). The study found that the use of connectors by students is challenging, considering the errors they made. Specifically, the study revealed that the percentage of errors decreased as students advanced in their training as follow: 30\%, 29\%, 27\%, and 14\% in first, second, third, and fourth year respectively. The results led to the conclusion that the students' level in using connectors (or DMs) improves as their academic level evolves. However, these finding may not be authentic due to the fact that the study is based on a small sample of 40 students only. However, longitudinal studies are very scarce and the researcher notices that most studies which were conducted on the use of connectors adopted a cross-sectional approach. In relation with this idea, Gilquin and Granger (2015, p.10) suggest that there is "need of more longitudinal studies covering the full interlanguage continuum (from beginner to advanced) to complement the cross-sectional studies that have been the backbone of LCR (Learner Corpus Research) to date." In addition to focusing crosssectional data; it is clear that no study targeted learners speaking an African language, and Kirundi in particular. This paper aims, therefore, to investigate the use of connectors on the basis of pseudo-longitudinal data consisting of essays written by first, second, and third-year undergraduate students from the University of Burundi.

\subsection{Model}

The present study is based on a model of connectors that was adapted from Quirk et al.'s (1985) framework. In addition, a comprehensive list counting 95 connectors classified into 6 categories was obtained after merging Tang and Ng's (1995), and Carrió-Pastor's (2013) lists of connectors. Let us indicate that these two studies were carried out on the use of connectors by EFL learners on the basis of Quirk et al.'s (1985) framework. Quirk et al. (1985, p.634) made a classification consisting of 7 categories of connectors (referred to as conjuncts in their work). These categories are listing, summative, appositive, resultive, inferential, contrastive as well as transitional connectors. The 7 categories are exemplified below:

Listing (2 sub-categories)

- Enumerative: e.g. First, first of all, secondly, etc.

- Additive (2 sub-categories): i) Equative: e.g. Equally, likewise, simlarly, etc..; ii) Reinforcing: E.g. In fact, indeed, in addition, etc.

Summative: e.g. In short, in conclusion, in sum, etc.

Appositive: e.g. Namely, for example, that is, in other words, etc.

Resultive (2 sub-categories):

-Causal: e.g. Because, for, as, etc.

- Resultive: Consequently, therefore, then, etc.

Inferential: e.g. Otherwise, in that case, then, etc.

Contrastive (4 sub- categories):

- Reformulatory: e.g. Rather, more accurately, more precisely, etc.

- Replacive: e.g. Alternatively, on the other hand, etc.

-Antithetic: e.g. While, whereas, in contrast, etc.

-Concessive: e.g. Anyway, in any case, all the same, etc. 
Transitional (2 sub-categories):

- Discoursal: e.g. By the way, incidentally, etc.

- Temporal: e.g. Meanwhile, subsequently, etc.

It should be noticed that some of these categories have sub-categories. For example, the listing category is subdivided into 2 sub-categories, namely enumerative and additive. In turn, the additive sub-category is further subdivided into two categories, i.e., equative and reinforcing. For the sake of simplicity in the analysis of the data, the sub-categories proposed by Quirk et al. (1985) are not considered in this work.

Among the 7 categories proposed by Quirk et al.'s (1985), we distinguish the resultive and inferential categories. The difference between the two types of connectors can be highlighted on the basis of explanations provided by Quirk et al. (1985) and Biber et al. (1999). According to Quirk et al. (1985), "inferential conjuncts indicate a conclusion based on logic and supposition" (p. 638). The following illustration is given: You haven't answered my question, in other words, you disapprove of my proposal. In turn, Biber et al. (1999) indicate that "linking adverbials in the result/ inferential category show that the second unit of discourse states the result or consequence of the preceding discourse - either logical or practical" (p.877). To the researcher's understanding, the difference between resultive and inferential connectors lies in the fact that resultive connectors introduce a result or consequence based on facts whereas inferential connectors express a result or consequence based on logic. In the researcher's view, this difference is quite subtle. As a result, with the Burundian learners' writing it was impossible to tell for sure if a connector was in the resultive or inferential category due to their low level in English. For this reason, the researcher decided not to emphasize the distinction between resultive and inferential categories but to merge them into one single category called resultive. This choice was made for the sake of intellectual honesty. Therefore, the list used in this study includes 6 categories, namely, listing, summative, appositive, resultive, contrastive, and transitional categories instead of 7 as proposed by Quirk et al. (1985).

Another important point to make is that while Quirk et al.'s (1985) framework and others such as Biber et al. (1999), Halliday and Hassan (1976) are indispensable references in the study of connectors, they do not offer comprehensive lists of connectors. The researcher noticed, for example, the absence of the connector "in fact" from all models consulted. Yet, from the researcher's teaching experience, it seems that this connector "in fact", which is in the listing category, is among the most preferred connectors by the EFL learners from the University of Burundi. This is the reason why, in addition to Quirk et al. (1985), two other works were consulted, i.e., Tang and Ng (1995) and CarrióPastor (2013). These two studies were both carried out on the use of connectors by EFL learners. They were, therefore, consulted in order to get a more comprehensive list of connectors for the present study. The list of connectors used in this study was obtained by merging the lists proposed by Tang and Ng (1995) and Carrió-Pastor (2013).

In a nutshell, a total of 95 connectors classified in 6 categories i.e., listing, summative, appositive, resultive, contrastive, and transitional were investigated in this study. This list is displayed in the following Table 1 below.

Table 1. List of connectors (adapted from Quirk et al., 1985)

\begin{tabular}{lll}
\hline Category & $\begin{array}{l}\text { Number of } \\
\text { connectors }\end{array}$ & \multicolumn{1}{c}{ Connector } \\
\hline Listing & 32 & $\begin{array}{l}\text { first, second, firstly, secondly, the second + noun, finally, further, furthermore, in } \\
\text { addition, moreover, lastly, last but not least, to begin with, in the first place, in the } \\
\text { second place, similarly, for one thing, for another thing, above all, for a start, in the } \\
\text { same way, likewise, third, thirdly, first of all, last, the last (reason/example, etc.), } \\
\text { last of all, in fact, first and foremost, next, another }\end{array}$
\end{tabular}

$\begin{array}{lll}\text { Summative } & 12 & \text { to sum up, to conclude, in summary, in sum, in short, in brief, in conclusion, } \\ \text { overall, all in all, altogether, in a nutshell, to summarize }\end{array}$


Appositive $10 \quad$ that is, that is to say, in other words, for instance, for example, namely, e.g., i.e., such as, specifically

Resultive 12 consequently, hence, therefore, thus, as a result, as a consequence, in consequence,
so, because, since, as, then

\begin{tabular}{lll}
\hline Contrastive 22 & $\begin{array}{l}\text { however, although, even though, though, on the other hand, instead, after all, on } \\
\text { contrary, nevertheless, in contrast, besides, anyway, still, nonetheless, alternati } \\
\text { rather, more precisely, in any case, by contrast, again, yet, in spite of }\end{array}$ \\
\hline Transitional 7 & $\begin{array}{l}\text { meanwhile, eventually, subsequently, originally, in the meantime, by the way, } \\
\text { incidentally }\end{array}$
\end{tabular}

Total 95

\section{Methodology}

\subsection{Design of the Study}

This study adopts the longitudinal approach, which requires collection of data at different stages from a group of subjects. Given time constraints, the researcher resorted to pseudo-longitudinal data, collected from first, second, and third-year students at the Institute for Applied Pedagogy at the University of Burundi. In addition, the corpus-based approach was adopted. This approach investigates language on the basis of language corpora and computer tools such as AntConc, WordSmith, and so on. Finally, the quantitative methods of analysis are used. Specifically, the present study uses AntConc tool (Anthony, 2018) to generate frequency information for connectors in students' writing.

\subsection{Instruments}

\subsubsection{The writing Assignment}

The data for this study were collected through 2 writing assignments which were given to students of years 1, 2, and 3 of the Institute for Applied Pedagogy, at the University of Burundi. The assignments were given in 2019. Each of the assignments consisted of 3 argumentative topics from which students had to choose only one topic. Students were given a variety of topics to ensure that each one would get a topic of interest to write about. The following are some examples of topics given: Polygamy should be banned in Burundi; Free access to the internet is one of the biggest threats to education. Students were given 2 hours to write an essay of 700 words about a topic of their choice.

\subsubsection{Questionnaire for Learner and Task Related Information}

In addition to writing of an essay, students were asked to answer a questionnaire designed to elicit information concerning the learner variable (such as their name, age, mother-tongue, other languages spoken, etc.) as well as the task variable (date, course, teacher). This information helped in the preparation of the metadata for the study. Let us indicate that these metadata, together with the learners' essays, will be used to design a web interface for the Burundian learner argumentative writing, which may be useful in the future for both teachers and learners as well as for researchers.

\subsection{Data Collection Procedures}

In connection with lecturers, the researcher gave 2 writing assignments to students who were registered in first, second and third year in 2019 at the University of Burundi, Institute for Applied Pedagogy, more precisely in the English Department. The students were given 2 hours to write a 700-word argumentative essay in class. They were not allowed to use reference books such as grammar books or dictionary. However before writing their essay, they filed a form which sought information about the writer and task variables. The duration between the 2 assignments was less than 
or equal to 2 months. In total, 622 essays were collected. Details concerning the contribution of essays is shown in the following table (Table 2).

Table 2. The contribution of essays

\begin{tabular}{cccc}
\hline Level & Task A & Task B & Total \\
\hline Bac 1 & 175 & 144 & 319 \\
\hline Bac 2 & 70 & 98 & 165 \\
\hline Bac 3 & 66 & 69 & 135 \\
\hline Total & 311 & 311 & 622 \\
\hline
\end{tabular}

\subsection{Data Coding}

Having collected the handwritten essays from the students, the next step was data coding. This was done in two steps. The first step was to have the essays typed to get machine readable data. This activity was done by a team of 5 former English students from the University of Burundi. At this step, the typists were warned not to modify the writers' texts i.e., they were given firm instructions not to correct the writers' errors or add any other errors as typists. Here, the researcher completely agrees with Gilquin's (2015) comment in her discussion about the challenges of turning handwritten texts into typed texts. She points out that keyboarding "can be quite tricky as the texts have to be reproduced exactly as they are, including the learners' errors but without introducing additional ones" (p.19). The texts were then edited by the typists in collaboration with the researcher. The next step consisted of preparing the "TXT" files and metadata for the corpus. In preparing TXT files, the researcher was looking for a format which is compatible with AntConc tool to be used in the analysis of the corpus.

\subsection{The Size of the Corpus}

The corpus for this study consists of 622 essays totaling 306, 664-word tokens as shown in Table 3 below.

Table 3. The size of the corpus

\begin{tabular}{cccc}
\hline $\begin{array}{c}\text { The sub- } \\
\text { corpora }\end{array}$ & Number of essays & Word types & Word tokens \\
\hline Bac1_A & 175 & 3,826 & 63,829 \\
\hline Bac 1_B & 144 & 4,311 & 68,528 \\
\hline Bac 2_A & 70 & 2,989 & 40,052 \\
\hline Bac 2_B & 98 & 3,862 & 64,366 \\
\hline Bac 3_A & 66 & 2,701 & 34,017 \\
\hline Bac 3_B & 69 & 2,885 & 35,872 \\
\hline Total & 622 & 8,920 & 306,664 \\
\hline
\end{tabular}

\subsection{Data Analysis Procedures}

As far as data analysis is concerned, the corpus was searched using AntConc tool in order to identify which connectors were used and how often they occurred in the corpus. Thanks to this tool, especially the concordance and start 
facilities, the researcher searched all the connectors investigated. To illustrate, let us consider an AntConc search for the connector "in summary", as displayed in Figure 1 below.

\begin{tabular}{|l|l|l|l|l|}
\hline AntConc 3.5.9 (Windows) 2020 & Concordance Concordance Plot File View Clusters/N-Grams Collocates Word List Keyword List \\
File Global Settings \\
Corpus Files
\end{tabular}

Figure 1. AntConc search results for the connector in summary

In this figure, a set of information should be understood. First, the sub-corpus searched consists of texts written by year 3 students (B3) which were written in response to the second assignment (B following the _ sign). As indicated in previous discussion, students were given two writing tasks. In addition, Figure 1 shows that there are 13 concordance hits (examples/occurrences) for the connector in summary. The same search exercise was done for all the connectors investigated and the number of examples for each connector was recorded in an XLS file. It should be noted that the search with AntConc was sometimes followed by manual sorting of the data. This was done in cases where the same could have several functions. For example, in the following sentences extracted from essays written by first year students, the word so is an adverb in (1) while it is a connector in (2).

1. Its [polygamy] consequences are so huge and some of them can be such as: hate among the wives, lack of satisfying the needs of the family, problems of schooling for the children and how ability in alimentation issue.

\section{Polygamy is a handicap in Burundi development so the government might take a measure to punish the people behave like that.}

Therefore, all the cases where the searched word did not play the role of connector were removed. Similarly, cases in which the function of the searched word (e.g. summative, resultive, etc.) was not clear were not counted. After the manual sorting of the data, the next step was to determine the frequency for each connector in percentage using XLS facility. 


\section{Results}

In this section, the researcher presents the results of the research. Based on frequency information provided by AntCon tool, the researcher calculated the total use and determined frequencies in percentages for all connectors investigated thanks to XLS facility. The results are presented in Table 4 below.

Table 4. Overall use of connectors by Burundian EFL learners

\begin{tabular}{|c|c|c|c|c|c|c|c|c|c|c|}
\hline & \multirow[t]{2}{*}{ Connectors } & \multirow[t]{2}{*}{$\begin{array}{l}\text { Connector } \\
\text { variants }\end{array}$} & \multicolumn{2}{|c|}{$\begin{array}{l}\text { Burundian } \\
\text { learners } 1\end{array}$} & \multicolumn{2}{|c|}{$\begin{array}{l}\text { Burundian } \\
\text { learners } 2\end{array}$} & \multicolumn{2}{|c|}{$\begin{array}{l}\text { Burundian } \\
\text { learners } 3\end{array}$} & \multirow[t]{2}{*}{$\begin{array}{l}\text { Total } \\
\text { use }\end{array}$} & \multirow[t]{2}{*}{$\%$} \\
\hline & & & $\begin{array}{l}\text { Text } \\
\text { A_174 } \\
\text { essays }\end{array}$ & $\begin{array}{l}\text { Text } \\
\text { B_143 } \\
\text { essays }\end{array}$ & $\begin{array}{l}\text { Text } \\
\text { A_70 } \\
\text { essays }\end{array}$ & $\begin{array}{l}\text { Text } \\
\text { B_98 } \\
\text { essays }\end{array}$ & $\begin{array}{l}\text { Text } \\
\text { A_66 } \\
\text { essays }\end{array}$ & $\begin{array}{l}\text { Text } \\
\text { B_69 } \\
\text { essays }\end{array}$ & & \\
\hline \multicolumn{11}{|c|}{ Listing } \\
\hline 1. & First & & 6 & 5 & 5 & 0 & 10 & 6 & 32 & 0,48 \\
\hline \multirow{3}{*}{2.} & \multirow{3}{*}{ Second } & 2a) second & 4 & 3 & 2 & 3 & 9 & 4 & 25 & 0,37 \\
\hline & & $\begin{array}{l}2 \mathrm{~b}) \text { on the } \\
\text { second hand }\end{array}$ & 0 & 0 & 0 & 0 & 0 & 1 & 1 & 0,01 \\
\hline & & $\begin{array}{l}\text { 2c) on the } \\
\text { second side }\end{array}$ & 0 & 0 & 0 & 1 & 0 & 2 & 3 & 0,04 \\
\hline 3. & Firstly & & 18 & 21 & 11 & 10 & 7 & 6 & 73 & 1,09 \\
\hline \multirow{3}{*}{4.} & \multirow{3}{*}{ Secondly } & 4a) secondly & 30 & 22 & 15 & 19 & 16 & 10 & 112 & 1,67 \\
\hline & & $\begin{array}{l}\text { 4b) } \\
\text { secondary }\end{array}$ & 2 & 3 & 3 & 6 & 1 & 4 & 19 & 0,28 \\
\hline & & $\begin{array}{l}4 c) \\
* \text { secondry }\end{array}$ & 1 & 0 & 0 & 0 & 0 & 0 & 1 & 0,01 \\
\hline 5. & $\begin{array}{l}\text { The } \\
\text { second+noun }\end{array}$ & & 2 & 0 & 2 & 0 & 2 & 0 & 6 & 0,09 \\
\hline 6. & Finally & & 25 & 24 & 7 & 13 & 5 & 3 & 77 & 1,14 \\
\hline 7. & Further & & 0 & 0 & 0 & 0 & 0 & 1 & 1 & 0,01 \\
\hline \multirow{2}{*}{8.} & \multirow{2}{*}{ Furthermore } & $\begin{array}{l}\text { 7a) } \\
\text { furthermore }\end{array}$ & 14 & 11 & 9 & 13 & 5 & 7 & 59 & 0,88 \\
\hline & & $\begin{array}{l}\text { 7b) *further } \\
\text { more }\end{array}$ & 3 & 5 & 0 & 1 & 0 & 3 & 12 & 0,18 \\
\hline 9. & In addition & & 61 & 48 & 17 & 35 & 13 & 16 & 190 & 2,83 \\
\hline \multirow{2}{*}{\multicolumn{2}{|c|}{ 10. Moreover }} & $\begin{array}{l}10 \text { a) } \\
\text { moreover }\end{array}$ & 43 & 40 & 17 & 20 & 19 & 16 & 155 & 2,30 \\
\hline & & $\begin{array}{l}10 \mathrm{~b}) \\
* \text { morover }\end{array}$ & 1 & 0 & 0 & 0 & 0 & 1 & 2 & 0,03 \\
\hline 11. & Lastly & & 4 & 1 & 0 & 3 & 6 & 3 & 17 & 0,25 \\
\hline 12. & Last but not least & & 1 & 0 & 1 & 0 & 0 & 0 & 2 & 0,03 \\
\hline
\end{tabular}




\begin{tabular}{|c|c|c|c|c|c|c|c|c|c|}
\hline 13. To begin with & & 0 & 0 & 0 & 0 & 0 & 2 & 2 & 0,03 \\
\hline 14. In the first place & & 0 & 0 & 0 & 0 & 0 & 0 & 0 & 0,00 \\
\hline $\begin{array}{l}\text { In the second } \\
\text { place }\end{array}$ & & 0 & 0 & 0 & 0 & 0 & 0 & 0 & 0,00 \\
\hline 16. Similarly & & 0 & 1 & 0 & 0 & 0 & 0 & 1 & 0,01 \\
\hline 17. For one thing & & 0 & 0 & 0 & 0 & 0 & 0 & 0 & 0,00 \\
\hline $\begin{array}{l}\text { For another } \\
\text { thing }\end{array}$ & & 0 & 0 & 0 & 0 & 0 & 0 & 0 & 0,00 \\
\hline 19. Above all & & 2 & 1 & 0 & 0 & 0 & 0 & 3 & 0,04 \\
\hline 20. For a start & & 0 & 0 & 0 & 0 & 0 & 0 & 0 & 0,00 \\
\hline 21. In the same way & & 6 & 0 & 0 & 0 & 0 & 0 & 6 & 0,09 \\
\hline 22. Likewise & & 1 & 0 & 0 & 1 & 0 & 0 & 2 & 0,03 \\
\hline 23. Third & & 1 & 1 & 1 & 7 & 5 & 0 & 15 & 0,22 \\
\hline \multirow{2}{*}{ 24. Thirdly } & 24a) thirdly & 10 & 6 & 7 & 8 & 7 & 7 & 45 & 0,67 \\
\hline & 24b) *firdly & 1 & 1 & 0 & 0 & 0 & 1 & 3 & 0,04 \\
\hline 25. First of all & & 21 & 27 & 15 & 21 & 14 & 12 & 110 & 1,64 \\
\hline 26. Last & & 0 & 0 & 0 & 0 & 0 & 2 & 2 & 0,03 \\
\hline $\begin{array}{l}\text { The last } \\
\text { 27. (reason/example, } \\
\text {...) }\end{array}$ & & 3 & 0 & 0 & 3 & 0 & 4 & 10 & 0,15 \\
\hline 28. Last of all & & 0 & 0 & 0 & 0 & 0 & 0 & 0 & 0,00 \\
\hline 29. In fact & & 57 & 45 & 33 & 41 & 20 & 28 & 224 & 3,33 \\
\hline 30. $\begin{array}{l}\text { First and } \\
\text { foremost }\end{array}$ & & 1 & 0 & 0 & 0 & 0 & 0 & 1 & 0,01 \\
\hline 31. Next & & 0 & 1 & 1 & 2 & 0 & 0 & 4 & 0,06 \\
\hline \multirow[t]{2}{*}{ 32. Another } & & 7 & 6 & 8 & 13 & 8 & 4 & 46 & 0,68 \\
\hline & & & & & & & & & \\
\hline 33. To sum up & & 2 & 4 & 7 & 17 & 8 & 3 & 41 & 0,61 \\
\hline 34. To conclude & & 5 & 7 & 7 & 10 & 12 & 9 & 50 & 0,74 \\
\hline 35. In summary & & 0 & 0 & 0 & 0 & 0 & 0 & 0 & 0,00 \\
\hline 36. In sum & & 0 & 0 & 0 & 0 & 1 & 1 & 2 & 0,03 \\
\hline \multirow[b]{2}{*}{ 37. In short } & $37 a)$ in short & 2 & 0 & 5 & 8 & 2 & 2 & 19 & 0,28 \\
\hline & $\begin{array}{l}37 \mathrm{~b}) * \text { in } \\
\text { short words }\end{array}$ & 0 & 0 & 0 & 0 & 0 & 1 & 1 & 0,01 \\
\hline 38. In brief & & 2 & 1 & 1 & 0 & 0 & 0 & 4 & 0,06 \\
\hline 39. In conclusion & $\begin{array}{l}39 a) \text { in } \\
\text { conclusion }\end{array}$ & 26 & 28 & 24 & 30 & 12 & 13 & 133 & 1,98 \\
\hline
\end{tabular}




\begin{tabular}{|c|c|c|c|c|c|c|c|c|c|}
\hline & $\begin{array}{l}39 \mathrm{~b}) * \text { as } \\
\text { conclusion }\end{array}$ & 6 & 11 & 2 & 1 & 2 & 3 & 25 & 0,37 \\
\hline & $\begin{array}{l}39 \mathrm{c}) * \text { as a } \\
\text { conclusion }\end{array}$ & 2 & 3 & 1 & 2 & 0 & 0 & 8 & 0,12 \\
\hline 40. Overall & & 0 & 0 & 0 & 0 & 1 & 0 & 1 & 0,01 \\
\hline 41. All in all & & 15 & 7 & 11 & 6 & 4 & 2 & 45 & 0,67 \\
\hline 42. Altogether & & 0 & 0 & 0 & 1 & 0 & 0 & 1 & 0,01 \\
\hline 43 In a nutshell & & 3 & 2 & 2 & 4 & 7 & 6 & 24 & 0,36 \\
\hline \multirow[t]{2}{*}{ 44. To summarize } & & 1 & 0 & 0 & 0 & 0 & 0 & 1 & 0,01 \\
\hline & & & & & & & & & \\
\hline 45. That is & & 7 & 0 & 12 & 10 & 11 & 15 & 55 & 0,82 \\
\hline 46. That is to say & & 3 & 1 & 0 & 0 & 0 & 0 & 4 & 0,06 \\
\hline 47. In other words & & 2 & 2 & 0 & 1 & 6 & 4 & 15 & 0,22 \\
\hline 48. For instance & & 41 & 37 & 23 & 35 & 19 & 26 & 181 & 2,69 \\
\hline \multirow{4}{*}{ 49. For example } & $\begin{array}{l}\text { 49a) for } \\
\text { example }\end{array}$ & 116 & 130 & 62 & 114 & 51 & 45 & 518 & 7,70 \\
\hline & $\begin{array}{l}\text { 49b) } * \text { for } \\
\text { examples }\end{array}$ & 7 & 1 & $1 \mathrm{j}$ & 0 & 1 & 0 & 10 & 0,15 \\
\hline & $\begin{array}{l}\text { 49c) *for } \\
\text { examples }\end{array}$ & 0 & 1 & 0 & 0 & 1 & 0 & 2 & 0,03 \\
\hline & $\begin{array}{l}\text { 49d) } * \text { for } \\
\text { example }\end{array}$ & 2 & 3 & 4 & 4 & 1 & 0 & 14 & 0,21 \\
\hline 50. Namely & & 0 & 1 & 1 & 0 & 1 & 0 & 3 & 0,04 \\
\hline 51. e.g. & & 0 & 0 & 0 & 0 & 2 & 0 & 2 & 0,03 \\
\hline 52. i.e. & & 0 & 0 & 0 & 0 & 0 & 0 & 0 & 0,00 \\
\hline 53. Such as & & 56 & 48 & 21 & 55 & 27 & 41 & 248 & 3,69 \\
\hline \multirow[t]{2}{*}{ 54. Specifically } & & 1 & 0 & 0 & 0 & 0 & 0 & 1 & 0,01 \\
\hline & & & & & & & & & \\
\hline 55. Consequently & & 4 & 11 & 6 & 5 & 5 & 5 & 36 & 0,54 \\
\hline 56. Hence & & 2 & 3 & 4 & 2 & 4 & 0 & 15 & 0,22 \\
\hline 57. Therefore & & 36 & 31 & 39 & 43 & 27 & 23 & 199 & 2,96 \\
\hline 58. Thus & & 21 & 9 & 14 & 5 & 3 & 9 & 61 & 0,91 \\
\hline 59. As a result & & 5 & 2 & 5 & 8 & 3 & 3 & 26 & 0,39 \\
\hline 60. $\begin{array}{l}\text { As a } \\
\text { consequence }\end{array}$ & & 0 & 0 & 0 & 0 & 0 & 0 & 0 & 0,00 \\
\hline 61. In consequence & & 0 & 0 & 0 & 0 & 0 & 0 & 0 & 0,00 \\
\hline 62. So & & 46 & 53 & 17 & 24 & 23 & 15 & 178 & 2,65 \\
\hline
\end{tabular}




\begin{tabular}{|c|c|c|c|c|c|c|c|c|c|}
\hline 63. Because & & 602 & 685 & 357 & 523 & 235 & 272 & 2674 & 39,76 \\
\hline 64. Since & & 4 & 3 & 10 & 32 & 17 & 16 & 82 & 1,22 \\
\hline 65. As & & 6 & 11 & 0 & 5 & 3 & 10 & 35 & 0,52 \\
\hline 66. Then & & 7 & 4 & 11 & 16 & 17 & 13 & 68 & 1,01 \\
\hline \multicolumn{10}{|l|}{ Contrastive } \\
\hline 67. However & & 25 & 27 & 18 & 17 & 16 & 20 & 123 & 1,83 \\
\hline 68. Although & & 11 & 22 & 4 & 12 & 1 & 6 & 56 & 0,83 \\
\hline 69. Even though & & 17 & 14 & 18 & 27 & 2 & 14 & 92 & 1,37 \\
\hline 70. Though & & 0 & 2 & 1 & 35 & 6 & 7 & 51 & 0,76 \\
\hline $\begin{array}{l}\text { 71. On the other } \\
\text { hand }\end{array}$ & & 8 & 5 & 8 & 6 & 7 & 6 & 40 & 0,59 \\
\hline \multirow{3}{*}{ 72. Instead } & 72a) instead & 1 & 1 & 5 & 5 & 0 & 3 & 15 & 0,22 \\
\hline & $\begin{array}{l}72 b) \text { instead } \\
\text { of }\end{array}$ & 17 & 45 & 14 & 58 & 8 & 22 & 164 & 2,44 \\
\hline & $\begin{array}{l}72 \mathrm{c}) \text { instead } \\
\text { to }\end{array}$ & 0 & 2 & 0 & 4 & 0 & 0 & 6 & 0,09 \\
\hline 73. After all & & 2 & 0 & 0 & 0 & 1 & 0 & 3 & 0,04 \\
\hline 74. On the contrary & & 1 & 0 & 2 & 0 & 0 & 1 & 4 & 0,06 \\
\hline 75. Nevertheless & & 4 & 5 & 2 & 3 & 2 & 0 & 16 & 0,24 \\
\hline 76. In contrast & & 4 & 0 & 0 & 0 & 0 & 3 & 7 & 0,10 \\
\hline 77. Besides & & 1 & 8 & 0 & 3 & 2 & 6 & 20 & 0,30 \\
\hline 78. Anyway & & 1 & 3 & 2 & 1 & 0 & 0 & 7 & 0,10 \\
\hline 79. Still & & 1 & 0 & 0 & 0 & 0 & 0 & 1 & 0,01 \\
\hline 80. Nonetheless & & 0 & 0 & 0 & 0 & 0 & 0 & 0 & 0,00 \\
\hline 81. Alternatively & & 0 & 0 & 0 & 1 & 0 & 0 & 1 & 0,01 \\
\hline 82. Rather & & 1 & 1 & 2 & 8 & 4 & 4 & 20 & 0,30 \\
\hline 83. More precisely & & 0 & 0 & 0 & 0 & 0 & 0 & 0 & 0,00 \\
\hline 84. In any case & & 0 & 0 & 0 & 0 & 0 & 0 & 0 & 0,00 \\
\hline 85. By contrast & & 0 & 0 & 0 & 1 & 0 & 1 & 2 & 0,03 \\
\hline 86. Again & & 4 & 3 & 0 & 5 & 0 & 3 & 15 & 0,22 \\
\hline 87. Yet & & 0 & 1 & 1 & 2 & 2 & 3 & 9 & 0,13 \\
\hline \multirow[t]{2}{*}{ 88. In spite of } & & 0 & 0 & 0 & 2 & 0 & 0 & 2 & 0,03 \\
\hline & & & & & & & & & \\
\hline 89. Meanwhile & & 1 & 1 & 1 & 0 & 0 & 0 & 3 & 0,04 \\
\hline 90. Eventually & & 0 & 0 & 0 & 0 & 1 & 0 & 1 & 0,01 \\
\hline 91. Subsequently & & 0 & 0 & 0 & 0 & 0 & 0 & 0 & 0,00 \\
\hline
\end{tabular}




\begin{tabular}{llllllllll}
\hline 92. & Originally & 0 & 0 & 0 & 0 & 0 & 0 & 0 & 0,00 \\
\hline 93. & In the meantime & 0 & 0 & 0 & 0 & 0 & 0 & 0 & 0,00 \\
\hline 94. & By the way & 12 & 8 & 3 & 0 & 0 & 1 & 24 & 0,36 \\
\hline 95. & Incidentally & 0 & 0 & 0 & 0 & 0 & 0 & 0 & 0,00 \\
\hline Total & & & & & & & 6725 & 100,00 \\
\hline
\end{tabular}

The analysis of the results displayed in Table 4 above reveals that the majority of the connectors investigated were used by EFL learner writers from the University of Burundi. Specifically, out of 95 connectors investigated, 78 connectors were used by learners representing $82.1 \%$. Only 17 connectors (representing $17.9 \%$ ) were not used at all levels. These are in the first place, in the second place, for one thing, for another thing, for a start, last of all, in summary, i.e., as a consequence, in consequence, nonetheless, more precisely, in any case, subsequently, originally, in the meantime and incidentally. These results suggest that the Burundian EFL learners, at all levels, are in general aware of the importance of connectors in writing.

Concerning the most frequently used connectors, the results of this study show that out of a total of 95 connectors investigated, 19 connectors are frequently used by Burundian EFL learners. Attention should be drawn on the fact that previous research on the use of connectors by learner writers has used the terms "overuse" and "underuse." However, what these terms mean is not yet clear. For the purposes of this study, we consider that a connector is "frequently used" or overused if it represents $1 \%$ and above. In Burundian learner writing, the most frequently used connectors are because, for example, such as, in fact, therefore, in addition, for instance, so, instead of, moreover, in conclusion, however, secondly, first of all, even though, since, finally, firstly and then. These are presented in descending order of importance together with their frequencies and corresponding reference number in the following table 5 below.

Table 5. The most frequently used connectors by Burundian EFL learners

\begin{tabular}{lllll}
\hline Rank & Connector & $\begin{array}{l}\text { Reference } \\
\text { number in } \\
\text { Table } 4\end{array}$ & Category & Frequency in \% \\
\hline 1. & Because & 63 & Resultive & 39.76 \\
\hline 2. & For example & $46 \mathrm{a}$ & Appositive & 7.70 \\
\hline 3. & Such as & 53 & Appositive & 3.69 \\
\hline 4. & In fact & 29 & Listing & 3.33 \\
\hline 5. & Therefore & 57 & Resultive & 2.96 \\
\hline 6. & In addition & 9 & Listing & 2.83 \\
\hline 7. & For instance & 48 & Appositive & 2.69 \\
\hline 8. & So & 62 & Resultive & 2.65 \\
\hline 9. & Instead of & $72 \mathrm{~b}$ & Contrastive & 2.44 \\
\hline 10. & Moreover & $9 \mathrm{a}$ & Listing & 2.30 \\
\hline 11. & In conclusion & $39 \mathrm{a}$ & Summative & 1.98 \\
\hline 12. & However & 67 & Contrastive & 1.83 \\
\hline 13. & Secondly & $4 \mathrm{a}$ & Listing & 1.67 \\
\hline 14. & First of all & 25 & Listing & 1.64 \\
\hline
\end{tabular}




\begin{tabular}{lllll}
\hline 15. & Even though & 69 & Contrastive & 1.37 \\
\hline 16. & Since & 64 & Resultive & 1.22 \\
\hline 17. & Finally & 10 & Listing & 1.14 \\
\hline 18. & Firstly & 3 & Listing & 1.09 \\
\hline 19. & Then & 66 & Resultive & 1.01 \\
\hline
\end{tabular}

As Table 4 shows, because is by far the most frequently used connector representing $39.76 \%$, followed by for example (7.70\%), such as $(3.69 \%)$ and in fact (3.33\%). Other most frequently used connectors are therefore (2.96\%), in addition (2.83\%), for instance (2.69\%), so (2.65\%), instead of (2.44\%), and moreover $(2.30 \%)$, etc. In terms of category, the results show that frequently used connectors are found in all categories except in the transitional category. In addition, it is obvious that the listing category is the most preferred one with in fact coming at the top. The resultive category is the next preferred category with because as the most preferred connector. The contrastive and appositive categories also occur but to a lesser extent than the listing and resultive categories. The summative category counts only one frequently used connector, that is, in conclusion. Finally, the transitional category is the only one which does not have any frequently used connectors. Table 6 below summarizes the Burundian EFL learners' preferences in terms of category.

Table 6. The Burundian EFL learners' preference in terms of categories

\begin{tabular}{lll}
\hline Category & $\begin{array}{l}\text { Number of preferred } \\
\text { connectors }\end{array}$ & Preferred connectors \\
\hline Listing & 7 & in fact, in addition, moreover, secondly, first of all, finally, firstly. \\
\hline Resultive & 5 & because, therefore, so, since, then \\
\hline Contrastive & 3 & instead of, however, even though \\
\hline Appositive & 3 & for example, such as, for instance \\
\hline Summative & 1 & in conclusion \\
\hline Transitional & 0 & \\
\hline Total & 19 & \\
\hline
\end{tabular}

From Table 6, we can see that the listing category is the most preferred one counting more frequently used connectors. On the other hand, the transitional category counts no frequently used connectors. This paradox, whereby some categories are preferred while others are not, is portrayed in the following graphs representing, respectively, the listing and the transitional categories. 


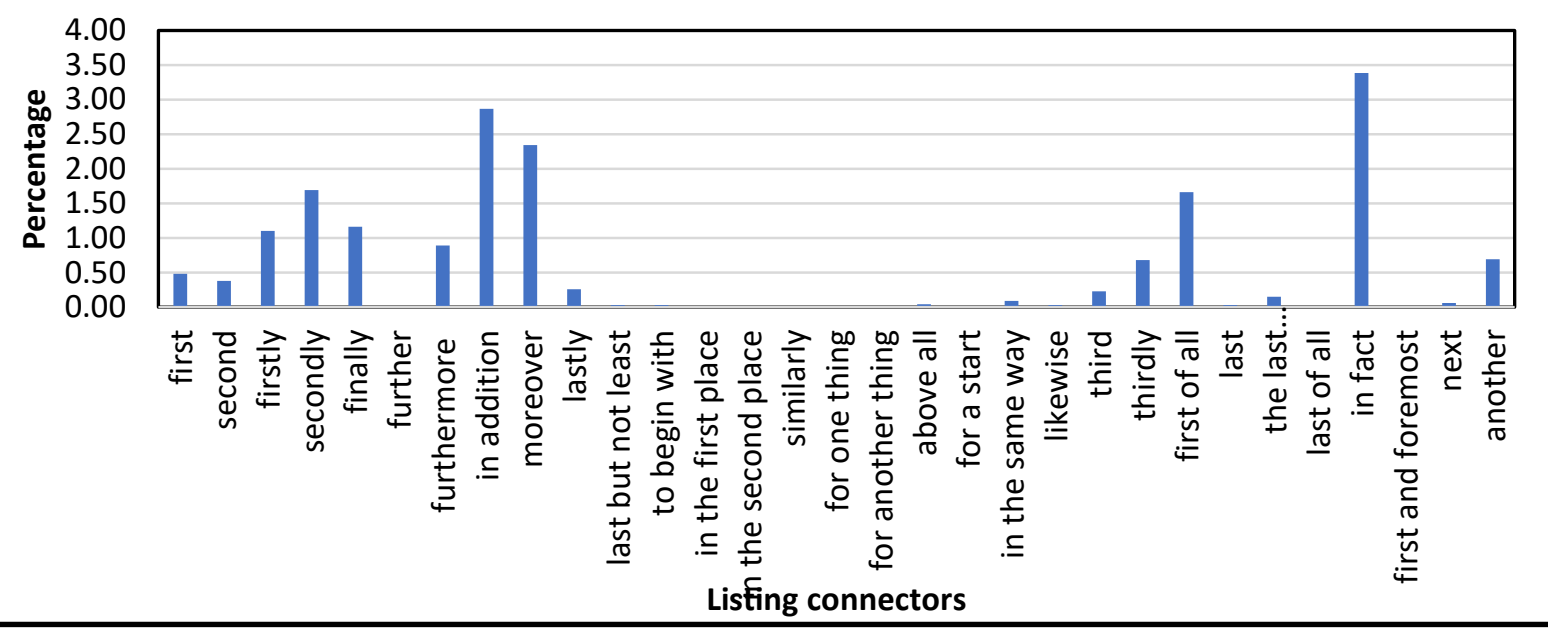

Figure 2. Frequency of listing connectors in Burundian EFL writing

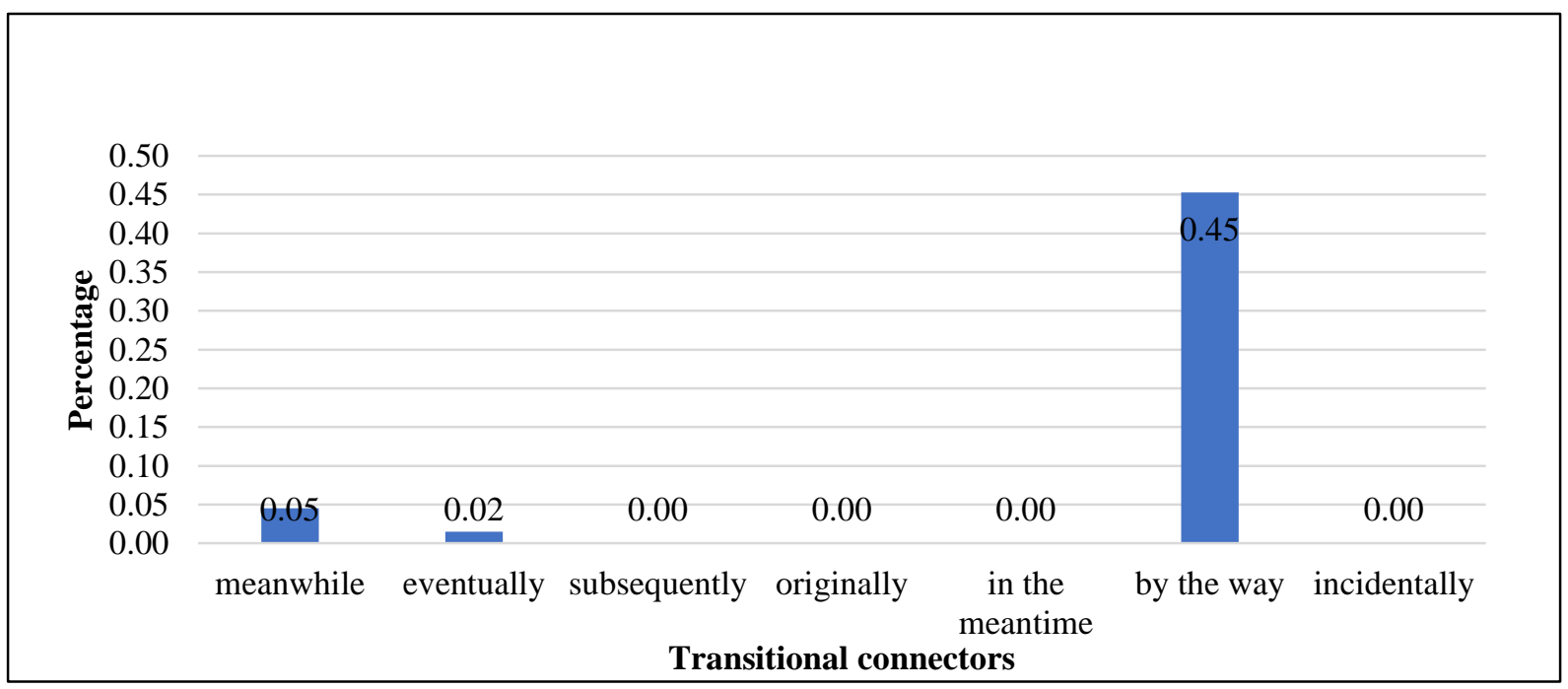

Figure 3. The frequency of transitional connectors in Burundian EFL writing

The listing category counts 31 connectors. It is the richest category. Out of these 31 connectors, 7 are frequently used by Burundian EFL learners with in fact coming at top. On the contrary, the transitional category counts only 7 connectors. Among these, no one is frequently used in the Burundian EFL learner writing. In this category, the connector with the highest percentage is by the way representing $0.45 \%$. Since this connector's percentage is below $1 \%$, we classify it in the group of underused connectors.

Another important point to make is that Burundian EFL writers at all levels seem to have the same preferences in terms of connectors. Consider, for example, the connector in fact which is very much preferred by Burundian EFL learners. We find many examples of this connector at all levels. There are 102 examples in year 1, 74 in year 2, and 48 examples in year 3. The same tendency is observable for the connector for instance which is also favoured by Burundian EFL learners. We find 78 examples of it in year 1, 58 examples in year 2, and 42 examples in year 3. In contrast, the word hence is underused in the Burundian learner corpus. We find 5 examples in year 1, 6 examples in 
year 2, and 4 examples in year 3. Another example of underuse is nevertheless. We find 9 examples in year 1, 5 examples in year 2, and 2 examples in year 3. Still another example of underuse is namely. We have 1 example of it in year 1,1 example in year 2, and 1 example in Year 3. These examples confirm the fact that this group of learners has the same preferences in the matter of connector use. This tendency also applies to connector misuse which is discussed below.

So far, we have discussed on issues related to the frequency of connectors in learner's writing. However, the results of this study also indicate that learners at all levels still encounter difficulties in the use of some connectors. In fact, the examination of results displayed in Table 4 above shows that some of the connectors investigated have variants in the learners' writing, corresponding to the learners' errors. For example, the connector secondly (see item 4 in Table 4) has three variants, namely, secondly, secondary as well as *secondry. This variation resulted from a spelling error on the part of learners who confused secondary and *secondry with secondly. Another example concerns the connector in conclusion (item 39 in Table 4). This connector has 5 variants, namely in conclusion, as conclusion, by conclusion, in a conclusion, as a conclusion. The correct combination is in conclusion and the other variants result from wrong word combinations on the part of learners. Following are some of the errors related to spelling and word combination as well as those resulting from confusion of words, as represented in Table 7 below.

Table 7. Misuse of connectors related to spelling and wrong combinations

\begin{tabular}{lll}
\hline Correct form & Incorrect form(s) & Problem \\
\hline in conclusion & as conclusion & wrong combination \\
& as a conclusion & \\
& by conclusion & \\
& in a conclusion
\end{tabular}

\begin{tabular}{lll}
\hline in short & in short words & wrong combination \\
\hline Secondly & secondary, *secondry & confusion and spelling \\
\hline Furthermore & $*$ further more & Spelling \\
\hline Thirdly & $*$ firdly & Spelling \\
\hline second/secondly & on the second hand & wrong combination \\
& on the second side & Spelling \\
\hline Moreover & $*$ moreover & Spelling \\
\hline for example & for examples & \\
& $*$ for exemples & \\
\hline
\end{tabular}

It is noticeable that these errors are made at all levels, years 1, 2, and 3. Let us take the example of as conclusion. We have 17 examples in year 1, 3 examples in year 2, and 5 examples in year 3 . In total we have 25 examples representing $0.37 \%$. Another example of misuse is the word secondary which is confused with the connector secondly. We have 5 examples in year 1, 9 examples in year 2, and 5 examples in year 3 totalling 19 examples. Secondary represents 0.28 $\%$ of all the connectors investigated. More cases of misuse exist in the corpus such as in fact used without a comma. (E.g. .... bstitute the prostitution with other activities. In fact too many leaders have been trying to (AntConc result, year 1). Following are some examples of misuse of the connector in conclusion in year 1, 2, and 3. 
As conclusion, couples are allowed to make their love and in that time they have to know that even if they are in love they have to waiting for making a marriage without living together because to live together before a marriage causes many problem in life (year 1).

By conclusion, prostitution should be prohibited here in Burundi even all over the world because it has no education which is better for them even for us (year 2).

As a conclusion, it would be better to allow secondary school pupils to use mobile phone because most of the cases, mobile phones help them in many ways (year 3 ).

It should be indicated that not all learners' misuse of connectors is reflected in Table 2 above. We can mention, for example, the misuse of the connector so which is used to introduce the concluding paragraph and is therefore equated with in conclusion. Its overuse by Burundian EFL learners is also evidence of lack of stylistic awareness of this group of learners. Let us indicate that connector misuse will be discussed in much greater detail in another paper on the basis of qualitative analysis of the learners' writing, i.e., the teachers' assessment of the learners' essays.

\section{Discussion}

This study has shown that out of 95 connectors investigated, 78 connectors were used by learners at all levels and that only 17 connectors were not used. These results suggest that the learners investigated are aware of the need to use connectors in writing. The results also suggest that Burundian learners at all levels, year 1, 2, and 3 have the same tendency in the use of connectors, that is, they have the same preferences in terms of connector use. In terms frequency of individual connectors, this study has shown that, out of 95 connectors investigated, 19 connectors are frequently used by English majors from the University of Burundi. These are because, for example, such as, in fact, therefore, in addition, for instance, so, instead of, moreover, in conclusion, however, secondly, first of all, even though, since, finally, firstly, and then. As regards the preference of the categories, it has been revealed that most frequently used connectors are from the listing category followed by the resultive category. Within the listing category, the connector with the highest percentage is in fact. Contrastive and appositive categories are also frequently used but to a lower extent compared to the listing and resultive connectors. Concerning the summative category, it counts only one frequently used connector, namely in conclusion while the transitional category counts no frequently used connectors. Finally, the study has revealed that the learners targeted still have challenges in the use of connectors. For example, the analysis of the corpus has shown that some students, at all levels, use wrong combinations such as as a conclusion, as conclusion, in a conclusion, by conclusion, instead of the summative connector in conclusion.

A study conducted by Güneş (2017) reached similar results. The study showed that the most overused connectors by Turkish doctoral students are in the listing (called additive) and resultative categories. The listing (additive) and the resultive categories are also cited by Tang and $\mathrm{Ng}$ (1995) to be among the most frequently used categories. Concerning the transitional and summative connectors, the results of the present study are in line with Tang and $\mathrm{Ng}$ (1995). Their study reached the conclusion that transitional and summative connectors, among others, were found to be rarely used by first year students at City University of Hong Kong.

The findings of this study contrast with from those of Tapper (2005). Her study investigated how advanced Swedish EFL learners used connectors in argumentative essays in comparison with how native speakers of English (a group of American University students) used them. The study found that contrastive connectors were the most frequently used, followed by the resultive, the clarifying, and the additive (listing) connectors. When we analyze Tapper's (2005) results, we can see that the preference of the connectors is somehow reversed with contrastive connectors coming at the top.

As far as the listing/additive category is concerned, it seems to be one among the most preferred categories by many learner groups. This listing/additive category is cited as one among the most preferred categories in many studies such as Granger and Tyson (1996), Güneş (2017), and Tang and Ng (1995). Granger and Tyson (1996) found that the Louvain French EFL learners overused listing connectors and appositive connectors (called in their study additive and corroborative connectors respectively). They indicated that "learners use most frequently those connectors which add to, exemplify or emphasize a point rather than those which change the direction of the argument or take the argument logically forward" (p.20). They also reported that the same findings were reached by a study conducted by Field and Yip (1992) on the writing of Hong Kong students. The fact that the listing/additve category is one among the most favoured connectors by learner groups makes sense because, as Quirk et al. (1985), indicate, the listing role is "a basic language function" (p.636). Learners from the University of Burundi, like many other learner groups, though they are 
at an advanced level, remain babies in developing ideas since they prefer the most basic roles in connecting ideas in their writing. Care should be taken in designing course materials and teaching to ensure that learners are trained to use the more complex connecting roles in their writing. In addition, the connectors should be introduced to students in such a way that the latter might learn a variety in each category.

Concerning individual connectors, the results of this study reveal that one of the most overused connectors in Burundian EFL learner corpus is in fact. Granger and Tyson (1996) and Gilquin and Granger (2015) found similar results. These studies showed that French speakers investigated overused the connector in fact. This overuse was interpreted by the researchers as a result of transfer of the equivalent French "en fait" (p.12). Gilquin and Granger (2015) examined how learners of English from different mother tongue backgrounds used connectors. They found that French speaking learners (i.e., Bulgarian and Italian) overused "in fact" but that it was not the case in other groups. They, therefore, suggested that probably the overuse of the connector in fact had to do with transfer of the French equivalent "en fait." The Burundian EFL learners' overuse of the connector "in fact" is also probably a result of transfer of the equivalent "en fait"/ "au fait" which is very common in Kirundi-French code-switching as in "Ndashobora kuguha iyi invitation ukayintwarira kwa Karori? En faitlau fait jewe naramurondeye ndamubura" (Could you please give this invitation to Karori [name of a person]? En fait, je l'ai cherché mais je ne l'ai pas trouvé.). Let us indicate that French has an important role in Burundi. It is an official language, a status it shares with Kirundi, the native language of Burundi. This study has shown that French bears an influence on the learning of English at least in the domain of connectors.

Another important issue about the use of individual connectors by Burundian EFL learners is their lack of stylistic awareness. One example is their frequent use of the connector $s o$ in academic writing. The results of this study indicate that $s o$ is among the most frequently used connector in Burundian EFL learner writing. More precisely, so is the $8^{\text {th }}$ most frequently used connector (c.f. Table 3 above). Such a result contradicts Biber et al. (1999). This study investigated, on the basis of corpus data, how English language is used across different genres, namely, conversation, fiction, news, and academic prose. Concerning the use of connectors, the study found that, in academic prose, the connector so is rarely used while it is the most frequently used connector in conversation, whether British or American (p.887). Therefore, the overuse of the connector in fact by Burundian EFL learners is seen as resulting from their lack of stylistic awareness.

A no less important result that deserves discussion is the evident preference by Burundian EFL learners of the resultive connector because. In fact, because is the most preferred connector by this group of learners representing 39.76\% followed by for example representing $7.70 \%$. One can see that there exists a very wide gap between the frequencies of these two connectors. The high frequency of because may be explained by the fact that leaners have very limited resources in terms of alternative connectors within the resultive category, that is, students probably do not know a variety of words to express the same meaning such as since, as in Table 1. Students should be equipped with a variety of resources in order to write more effectively. It could also mean that Burundian learners like giving excuses or reasons for actions even when these are not necessary.

Finally, the results of this study indicated that Burundian EFL learners have many challenges in the use of connectors. These include semantic, stylistic, syntactic errors as well as errors related to word combination, spelling, and confusion of words. It is worth indicating that errors of spelling and confusion of connectors are not reported in the literature in any group of learners. Other authors reported other challenges but not those related to spelling. Granger and Tyson (1996), for example, analyzed argumentative essays written by French EFL learners in comparison with essays written by native speakers of English. The study revealed that the French EFL learners misused connectors on the semantic, stylistic, and syntactic levels. Thus, such errors of spelling and those resulting from confusion are evidence of a low level in English on the part of Burundian EFL writers which should be handled by all concerned steak-holders, namely, decision-makers, teachers, researchers, and students themselves.

\section{Conclusion}

The present study investigates how frequently English majors from the University of Burundi use connectors in their argumentative writing. The study was conducted on the basis of pseudo-longitudinal data collected in years 1,2, and 3 in the department of English, at the Institute for Applied Pedagogy. Adopting the corpus linguistic approach, the study analyzed 95 connectors classified into 6 categories. AntConc tool was used to search the corpus in order to find the targeted connectors. The results of this study indicate that learners at all levels tend to have the same preferences in terms of connectors and categories. In terms of category, it was found that the listing category is the most preferred 
one followed by the resultive while the contrastive and appositive categories were used to a lesser extent. Finally, the summative and transitional categories were found to be rarely used. In terms of individual connectors, it was found that 19 connectors out of 95 were frequently used by learners, the most frequently used ones being because, for example, such as, in fact, therefore, in addition, for instance, so, instead of, moreover, in conclusion, however, secondly, first of all, even though, since, finally, firstly, and then. Such a result is an indication of learners' awareness of the importance of connectors in academic writing.

This study has also revealed that "because" is by far the most preferred connector probably due to a lack of alternatives within the resultive category. Another connector which draws the researcher's attention is the connector in "fact" which is also preferred by Burundian EFL learners probably due to transfer from French phrases "en fait"/ "au fait" used in Kirundi-French codeswitching. Another important finding of this study is the fact that the targeted learners still have challenges in the use of connectors. Learners at all levels made errors related to spelling and wrong combination of words as well as syntactic, semantic, and stylistic errors. The errors encountered reveals that the learners targeted in this study have a low level in the use of connectors in particular. These results lead us to formulate a number of recommendations for both teaching and further research. Concerning the teaching of connectors, it should be based on corpus data so that learners have an appropriate context for learning. In this case, examples of connectors should be drawn from authentic language use. Another advantage of using corpus data is that teachers are able to anticipate learners' challenges. Furthermore, in teaching connectors, focus should be on helping learners master a variety of connectors in all categories. Teachers should also strive to give their learners opportunities to use them in communicative tasks. As regards future research, since many studies carried out on the use of connectors by EFL learners have reached contradictory results, more studies should be conducted on as many EFL learner groups as possible to gain more understanding of this aspect of language use. In addition, it has been clear from this research that most research on connectors has been carried out on the advanced level, future researchers should investigate the use of connectors at the intermediate level (i.e., secondary school level).

\section{References}

Al Mughrabi, F. M. (2017). Arab learners of English and the use of discourse markers in writing. Journal of Language Teaching and Research, 8(4), 715-721. http://dx.doi.org/10.17507/jltr.0804.10

Anthony, L. (2018). AntConc (Version 3.5.7) [Computer Software]. Tokyo, Japan: Waseda University.

Biber, D., Johansson, S., Leech, G., Conrad, S., \& Finegan, E. (1999). Longman grammar of spoken and written English. London: Pearson Education.

Byrne, D. (1979). Teaching writing skills. London: Longman.

Carrió-Pastor, M. L. (2013). A contrastive study of the variation of sentence connectors in academic English. Journal of English for Academic Purposes, 12(3), 192-202. http://dx.doi.org/10.1016/j.jeap.2013.04.002

Celce-Murcia, M., \& Larsen-Freeman, D. (1999). The grammar book: An ESL/EFL teacher's course. United States: Heinle \& Heinle Publishers.

Field, Y., \& Oi, Y. L. M. (1992). A comparison of internal conjunctive cohesion in the English essay writing of Cantonese speakers and native speakers of English. RELC Journal, 23(1), 15-28. https://doi.org/10.1177\%2F003368829202300102

Gilquin, G. (2015). From design to collection of learner corpora. In S. Granger, G. Gilquin, \& F. Meunier (Eds.), The Cambridge handbook of learner corpus research. Cambridge: Cambridge University Press.

Gilquin, G., \& Granger, S. (2015). Learner language. In D. Biber \& R. Reppen (Eds.) The Cambridge handbookf English corpus linguistics, Cambridge University Press, 418-435.

Granger, S. (1996). From CA to CIA and back: An integrated approach to computerized bilingual and learner corpora. In K. Aijmer, B. Altenberg, \& M. Johansson (Eds.), Languages in contrast (Lund Studies in English 88, pp. 37-51). Lund, Sweden: Lund University Press.

Granger, S., \& Tyson, S. (1996). Connector usage in the English essay writing of native and non-native EFL speakers of English. World Englishes, 15(1), 17-27. doi: 10.1111/j.1467-971X.1996.tb00089.x 
Güneş, H. (2017). A corpus-based study of linking adverbials through contrastive analysis of L1/L2 PhD dissertations. International Journal of Curriculum and Instruction, 9(2), 21-38. http://ijci.wcciinternational.org/index.php/IJCI/article/view/102

Halliday, M. A. K., \& Hassan, R. (1976). Cohesion in English. London and New York: Longman.

Leki, I. (1989). Academic writing: Techniques and tasks. New: York: St. Martin's Press.

Mahendra, M. W., \& Dewi, N. P. R. P. (2017). The use of transition signals in EFL academic writing context: a corpus study. Jurnal Bahasa Lingua Scientia, 9(1), 87-100. https://doi.org/10.21274/1s.v9i1.486

Matte, M. L. (2017). A corpus-based study of connectors in student academic writing. https://www.lume.ufrgs.br/bitstream/handle/10183/179593/001067985.pdf?sequence=1

Mauranen, A. (1993). Cultural differences in academic rhetoric: A text linguistic study. Frankfurt/Main: Peter Lang.

Milton, J. C., \& Tsang, E. S. C. (1993). A corpus-based study of logical connectors in EFL students' writing: Directions for future research. In Studies in lexis. Proceedings of a seminar on lexis organized by the language centre of the HKUST, Hong Kong (Language Centre, HKUST, Hong Kong, 1993). https://repository.ust.hk/ir/Record/1783.1-1083

Quirk, R., Greenbaum, S., Leech, G., \& Svartvik, J. (1985). A comprehensive grammar of the English language. London: Longman.

Sabzevari, A., Haghverdi, H., \& Biria, R. (2016). Sentence-initial conjunctive adverbials in academic articles written by native English speakers and Iranian EFL writers. Modern Journal of Language Teaching Methods, 6(5), 282.

Tang, E., \& Ng, C. (1995). A study on the use of connectives in ESL students' writing. Perspectives, 7(2), 105-121. https://www.semanticscholar.org/paper/A-Study-on-the-Use-of-Connectives-in-ESL-Students$\%$ E2\%80\%99/ab944befa98e6c38623315ff9772fb7b05f6c33d

Tapper, M. (2005). Connectives in advanced Swedish EFL learners' written English- preliminary results. The Department of English: Working Papers in English Linguistics, 5, 116-144. https://www.sol.lu.se/fileadmin/media/forskning/workingpapers/engelska/vol05/Tapper-wp-05.pdf

Uçar, S., \& Yukselir, C. (2017). A corpus-based study on the use of the logical connector 'thus' in the academic writing of Turkish EFL learners. English Language Teaching, 10(2), 64-72. https://eric.ed.gov/?id=EJ1126745 